\title{
Nanoscopic structure of complexes formed between DNA and the cell-penetrating peptide penetratin
}

Article

Accepted Version

de Mello, L. R., Hamley, I. W., Castelletto, V., Garcia, B. B. M., Han, S. W., de Oliveira, C. L. P. and da Silva, E. R. (2019) Nanoscopic structure of complexes formed between DNA and the cell-penetrating peptide penetratin. The Journal of Physical Chemistry B, 123 (42). pp. 8861-8871. ISSN 1520-5207 doi: https://doi.org/10.1021/acs.jpcb.9b05512 Available at https://centaur.reading.ac.uk/86280/

It is advisable to refer to the publisher's version if you intend to cite from the work. See Guidance on citing.

To link to this article DOI: http://dx.doi.org/10.1021/acs.jpcb.9b05512

Publisher: American Chemical Society

All outputs in CentAUR are protected by Intellectual Property Rights law, including copyright law. Copyright and IPR is retained by the creators or other copyright holders. Terms and conditions for use of this material are defined in the End User Agreement. 


\section{CentAUR}

Central Archive at the University of Reading

Reading's research outputs online 


\title{
Nanoscopic Structure of Complexes Formed Between DNA and the Cell Penetrating Peptide Penetratin
}

\author{
Lucas Rodrigues de Mello, ${ }^{\mathrm{a}}$ Ian William Hamley, ${ }^{\mathrm{b}}$ Valeria Castelletto, ${ }^{\mathrm{b}}$ Bianca Bonetto Moreno \\ Garcia, ${ }^{a}$ Sang Won Han, ${ }^{a}$ Cristiano Luis Pinto de Oliveira, ${ }^{\mathrm{c}}$ and Emerson Rodrigo da Silva ${ }^{\mathrm{a}^{*}}$ \\ a Departamento de Biofísica, Universidade Federal de São Paulo, São Paulo 04023-062, Brazil; \\ ${ }^{\mathrm{b}}$ Department of Chemistry, University of Reading, Reading RGD 6AD, United Kingdom; \\ 'Instituto de Física, Universidade de São Paulo, São Paulo 05508-090, Brazil.
}

\begin{abstract}
One of the most remarkable examples of cell-penetrating peptides (CPPs) is Penetratin, a 16-mer fragment derived from the Drosophila Antennapedia homeobox. Understanding the structure of Penetratin/DNA complexes is a key factor for the successful design of new vectors for gene delivery and may assist in optimizing molecular carriers based on CPPs. Herein, we present a comprehensive study on the nanoscale structure of noncovalent complexes formed between Penetratin and DNA. The strong cationic nature of the peptide makes it a very efficient agent for condensing DNA strands via electrostatic attraction and we show for the first time that condensation is accompanied by random-to- $\beta$-sheet transitions of peptide secondary structure, demonstrating that nucleic acids behave as a structuring agent upon complexation. For the first time, nanoscale-resolved spectroscopy is used to provide single-particle infrared data from DNA carriers based on CPPs and they show that the structures are stabilized by Penetratin $\beta$-sheet cores, whereas larger DNA fractions are preferentially located in the periphery of aggregates. Insolution infrared assays indicate that phosphate diester groups are strongly affected upon DNA condensation, presumably as consequence of charge delocalization induced by the proximity of cationic amide groups in Penetratin. The morphology is characterized by nano-assemblies with surface fractal features and short-range order is found in the inner structure of the scaffolds. Interestingly, the formation of beads-on-a-string arrays is found, producing nanoscale architectures that resemble structures observed in early steps of chromatin condensation. A complexation pathway where DNA condensation and peptide pairing into $\beta$-sheets are key steps for organization is proposed.
\end{abstract}

*Corresponding Author: er.silva@unifesp.br 


\section{INTRODUCTION}

Cell penetrating peptides (CPPs) are short amino acid sequences endowed with cell penetrating capabilities. ${ }^{1-3}$ The current literature reports more than $1500 \mathrm{CPPs},{ }^{4,5}$ displaying a huge variety of characteristics regarding their origin, internalization mechanisms ${ }^{6,7}$ and physicochemical behaviors. ${ }^{6,8}$ For instance, a large number of Trojan sequences have been isolated from transduction proteins whereas many others have been de novo designed in the laboratory. ${ }^{4,8}$ Also, several of them exhibit strong amphipathic features whereas others are almost exclusively composed by hydrophilic moieties. In this context of huge chemical diversity, common features shared by almost all cell-penetrating peptides are their reduced size, normally than 30 amino acid residues, and positive net charge.

One of the most known examples of CPP is so-called Penetratin, an arginine- and lysineenriched 16-mer fragment situated between positions 43 and 58 in the third helix of the Drosophila Antennapedia homeoprotein. ${ }^{10-12}$ Since its discovery in the mid 1990's, Penetratin has been successfully applied to translocate different cargoes into living cells ${ }^{13-15}$ and, more recently, a growing number of studies has reported on its use to deliver silencing RNAs into retinal

cells, ${ }^{16}$ to produce conjugates with metallic nanoparticles and polymer micelles, ${ }^{17,18}$ and to formulate conjugates able to invade the blood-brain barrier. ${ }^{17,19}$ Many of these delivery systems have been formulated by covalent conjugation with the load;, ${ }^{2,49}$ however, the highly-cationic composition makes Penetratin a powerful condensing agent for producing conjugates with nucleic acids through non-covalent strategies. ${ }^{11,20,21}$ The advantage of this approach is that preparation is easier and cheaper in comparison to synthesis of covalently bound conjugates, and complexation relies on weak interactions that facilitate ease of release. On the other hand, major drawbacks of non-covalent assemblies are their lower uptake efficiencies and higher complexity for structure determination since these entities can form aggregates with very complex secondary and tertiary structures. ${ }^{2,22,23}$ This last feature in particular represents a key issue either for establishing structure-activity relationships or to optimize the production of new vectors intended for gene delivery. ${ }^{2,4}$ In addition, the third helix at C-terminus of homeoproteins is known to dock 
with DNA major grooves ${ }^{24}$ and, although several homeodomains have been identified to date, this region is highly conserved among different homeoproteins. For instance, certain amino acids are systematically found at certain positions: $\mathrm{V}$ or I at $45, \mathrm{~W}$ at $48, \mathrm{~F}$ at $49, \mathrm{R}$ or $\mathrm{K}$ at 52,55 and $57 .{ }^{25,26}$ The Penetratin sequence obeys this prototypical composition and, therefore, information on supramolecular ordering of Penetratin/DNA condensates represents a potential contribution to shed light on the regulatory function of Antennapedia.

In the current work, we present a multi-level structural study on the organization of complexes formed between Penetratin and DNA. We show that Penetratin has strong condensing capabilities, driving nanoscopic condensation with both calf-thymus and plasmid DNA. The morphology is characterized by irregular aggregates exhibiting surface fractal features and shortrange order. The secondary structure of the aggregates is dominated by $\beta$-sheets, while random to $\beta$-sheets transitions are observed upon addition of DNA, demonstrating that nucleic acids behave as a structuring agent during complexation. Infrared data suggests the electrostatic attraction between opposite charges at amine and phosphate groups is the underlying force driving complexation and chemical bonding related to phosphate diester groups is strongly affected upon DNA condensation. Interestingly, the nanoscopic structure of condensates containing DNA fragments has been shown to display a beads-on-a-string architecture, resembling the morphology of aggregates found in the early steps of chromatin condensation. ${ }^{27}$

\section{MATERIALS AND METHODS}

Peptide synthesis, reagents and sample preparation: The Penetratin peptide (R-Q-I-K-I-W-FQ-N-R-R-M-K-W-K-K-NH ${ }_{2}$ ) was custom synthesized by AminoTech (São Paulo - Brazil), using routine solid-phase approaches through the Fmoc strategy as described elsewhere. ${ }^{28,29}$ TFA was used to cleave peptides from polymer resin and deprotect amino acid side-groups. Peptides were then precipitated with diethyl ether and the product was freeze-dried for a couple of days. During this step, TFA and other scavengers are removed along with the solvent. In the purification step, 
lyophilized crude peptides were resuspended in aqueous ACN + 0.1\% TFA solutions (60:40, v:v) and purified on a semi-preparative liquid chromatography system using C18 columns. The separated fraction containing purified peptides was lyophilized again for a period of days to ensure complete evaporation of the solvent. In the remaining peptide powder, trifluoro acetate counter-ions $\left(\mathrm{CF}_{3} \mathrm{CO}_{2}^{-}\right)$provide charge neutralization against cationic groups at the peptide, which is delivered as a TFA salt. Henceforth, the Penetratin peptide will be referred to as PNT. Liquid chromatography coupled to mass spectroscopy assays revealed purity and molecular mass, respectively, at 95\% and 2245.7 $\mathrm{Da}$ (calculated $\mathrm{M}_{\mathrm{w}}=2245.75 \mathrm{Da}$ ). Double-stranded DNA originated from calf thymus tissue was purchased from Sigma-Aldrich and characterized by agarose gel electrophoresis (SI file, Figure S1A). Ultrasonication was used as described elsewhere ${ }^{30-32}$ to fragment calf thymus DNA to sizes of $~ 200$ bp (Figure S1B). Since separation between consecutive base pairs along the B-form of DNA chains is about $0.34 \mathrm{~nm},{ }^{33}$ the size of these fragments can be estimated to be $\sim 200 \times 0.34=68 \mathrm{~nm}$, which is a bit longer than the persistence length of the DNA backbone $(50 \mathrm{~nm}) .{ }^{31}$ Therefore DNA fragments can be described as rod-like structures not able to fold, with diameter of $\sim 2 \mathrm{~nm} .{ }^{31,32}$ Stock solutions were prepared by weighing peptide powder or DNA fibers into Eppendorf tubes and re-suspending them in ultrapure water (or deuterated water, $\mathrm{D}_{2} \mathrm{O}$ ) to the desired concentrations. DNA stock solutions were left to rest in the fridge $\left(4^{\circ} \mathrm{C}\right)$ for periods of 2-3 days, with several vigorous vortexing cycles to assist homogenization. The complexes were prepared by mixing proper amounts from the stock solutions to obtain different ratios between cationic charges on the side chains of the PNT and anionic charges at phosphate groups of the DNA $\left(\mathrm{N}^{+}: \mathrm{P}^{-}\right.$ratio). $\mathrm{pH}$ assessment carried out either in peptide (or DNA) solutions or in mixtures with PNT/DNA complexes (1:1 molar charge ratio) revealed that our samples are slightly acidic, $\mathrm{pH} \sim 6$ (see SI file, Fig. S13). Therefore, peptide basic groups are protonated whereas DNA strands carry two negative charges per base pair. Since our peptides were synthesized with a $\mathrm{NH}_{2}$ group at C-terminus, charges were computed considering the protonated $\mathrm{N}$-terminus plus one positive charge per alkaline residue along the sequence, leading to a +8 net charge per Penetratin chain. In addition, since measurements were performed within a period of a few days from sample preparation, stability of DNA base-pairs is 
kept in the samples. ${ }^{34}$ The formation of white pellets upon mixture of PNT and DNA was observed in solutions containing DNA at concentrations above $>1 \mathrm{mg} / \mathrm{ml}$; in more dilute preparations, no visual phase separation appeared. The green fluorescent protein (GFP) expressing vector, pEGFP-N3, was acquired from BD (New Jersey, USA). Initially, Escherichia coli (DH5- $\alpha$ ) bacteria were transformed with pEGFP-N3 (Clontech, Mountain View, USA) and cultured in $2 \mathrm{~L}$. Bacteria mass obtained after centrifugation was used to pEGFP-N3 purification using Endo-free Megaprep kit from Qiagen (Hilden, Germany) following the provided instructions. Plasmid integrity was analyzed by agarose gel electrophoresis, and the plasmid concentration and quality were assessed by Nanodrop 2000 (Thermo Fisher Scientific, Massachusetts, EUA). ${ }^{34}$

Fourier-transform Infrared Spectroscopy (FTIR). Samples were prepared in deuterated water, $\mathrm{D}_{2} \mathrm{O}$, and examined on a Varian 610-IR spectrophotometer using an ATR accessory. Peptide concentration was kept at $1 \mathrm{mg} / \mathrm{ml}$ and the corresponding amount of DNA was added to match the desired $\mathrm{N}^{+}: \mathrm{P}^{-}$ratio. Droplets from solutions were placed on top of the germanium crystal and data were collected at $2 \mathrm{~cm}^{-1}$ resolution. After 128 accumulations, data were averaged and background-subtracted.

Circular Dichroism (CD). Solutions containing peptides dissolved into ultrapure water at 0.1 $\mathrm{mg} / \mathrm{ml}$ were loaded into Hellma cells with $1 \mathrm{~mm}$ path length. Titration assays were carried out by adding DNA from concentrated solutions to cover $\mathrm{N}^{+}: \mathrm{P}^{-}$ratios below and above the point of molar equivalence between positive and negative charges. Spectra were collected in the range 180-255 $\mathrm{nm}$, in steps of $1 \mathrm{~nm}$ and $1 \mathrm{~s}$ per step. Data from four accumulations were averaged and background subtracted, and conversion into ellipticity units has been performed by normalizing the data according to the peptide concentration in the solution. Only data exhibiting absorbance $<2$ were considered for analysis. Fourier filtering ( 7 points window) was used to minimize noise. A homemade MatLab routine was used to calculate linear combinations of $P N T$ and DNA spectra and compare the minimal residual result to the experimental data. 
Small-angle X-ray Scattering. Small-angle X-ray Scattering (SAXS) measurements were carried out using synchrotron sources at SAXS-1 LNLS (Campinas, Brazil) and BM29-ESRF (Grenoble, France). Data from PNT/DNA complexes were collected on SAXS-1, using white pellets precipitated from $P N T /$ DNA. Samples were left to equilibrate for $2-3$ days at $4{ }^{\circ} \mathrm{C}$ before SAXS experiments. The $P N T$ concentration was kept at $5 \mathrm{mg} / \mathrm{ml}$, while DNA concentration was adjusted to match the desired $\mathrm{N}^{+}: \mathrm{P}^{-}$ratio. The pellets were sandwiched between mica windows, with $1 \mathrm{~mm}$ path length, and SAXS data was acquired during $300 \mathrm{~s}$, at room temperature. Data collection was separated into ten successive frames to inspect radiation damage. Data from solutions containing only PNT or DNA were obtained on BM29 using the BioSAXS apparatus available on the beamline. The X-ray energy was set at $12 \mathrm{keV}$ and successive frames of $0.2 \mathrm{~s}$ each were registered during flow. The frames were averaged and scattering from water was subtracted to provided background correction. Complementary SAXS data were collected on a laboratory Xenocs-Xeuss instrument at Institute of Physics, University of São Paulo (see SI file for details). Small-angle neutron scattering (SANS) experiments were carried out on LOQ beamline at ISIS (see SI, file for details). In all cases the scattering intensity is displayed as a function of the reciprocal space momentum transfer modulus q, defined as $q=4 \pi \sin \theta / \lambda$, where $2 \theta$ is the scattering angle and $\lambda$ the radiation wavelength (see SI file for details).

Nanoscale Infrared measurements (AFM-IR). Nanospectroscopy measurements were performed using an Anasys NanoIR2-s instrument at LNNano. Droplets of PNT/DNA aqueous solutions (PNT at $0.5 \mathrm{mg} / \mathrm{ml}$ ) were deposited onto the surface of Au-coated silica substrates and left to rest for about 5 minutes. The substrates were then rinsed with ultrapure water and left to dry overnight into desiccators. All measurements were carried out at room temperature. AFM-IR is a relatively recent technique and it is based on the thermal expansion of the sample upon infrared absorption. ${ }^{35,36}$ Herein, the microscope was used in contact mode and substrates were illuminated by a tunable laser. ${ }^{37}$ For collecting IR spectra from individual aggregates, the AFM tip was positioned on the top of the particle whereas the laser source was varied in the range 1550 $-1800 \mathrm{~cm}^{-1}$, generating absorption spectra from the area underneath the tip (diameter $\sim 30 \mathrm{~nm}$ ). 
Chemical maps were obtained by fixing the laser source at specific wavenumbers (1670 or 1720 $\mathrm{cm}^{-1}$ ) and scanning the surface with the AFM tip. All data were baseline subtracted (Au profile) and smoothed using an FFT filter (7 points of window).

Transmission electron microscopy (TEM). Transmission electron microscopy imaging was carried out on a JEOL 2100 FEG-TEM microscope at LNNano, Campinas, Brazil. Samples were prepared by depositing complexes from $0.1 \mathrm{mg} / \mathrm{ml}$ solutions onto lacey Carbon grids (300 mesh) and letting them rest for $60 \mathrm{~s}$. The excess of solution was removed with filter paper. Droplets with $5 \mu \mathrm{l}$ of $2 \%$ uranyl acetate solution were deposited onto the grid and left to rest for $30 \mathrm{~s}$. The procedure for uranyl staining was repeated twice. The microscope was operated at $200 \mathrm{keV}$ acceleration voltage. Further data treatment was performed using Image $\mathbf{J}$ software.

\section{RESULTS AND DISCUSSION}

\section{Small-Angle Scattering}

We have performed small-angle X-ray Scattering (SAXS) to investigate the nanoscopic structure of PNT/DNA complexes. SAXS is powerful technique that provides structural data from samples under hydrated conditions, thus, being complementary to microscopy methods performed on dried specimens. Through these experiments, we have been able to get insights into the shape of aggregates and characteristic sizes such as radius of gyration. In addition, our data also revealed the presence of ordering in the inner part of the assemblies. The of $q$-range scanned in our experiments corresponds to length scales in the interval from 2 to $50 \mathrm{~nm}$ and should provide information on the supramolecular arrangement of the complexes. 


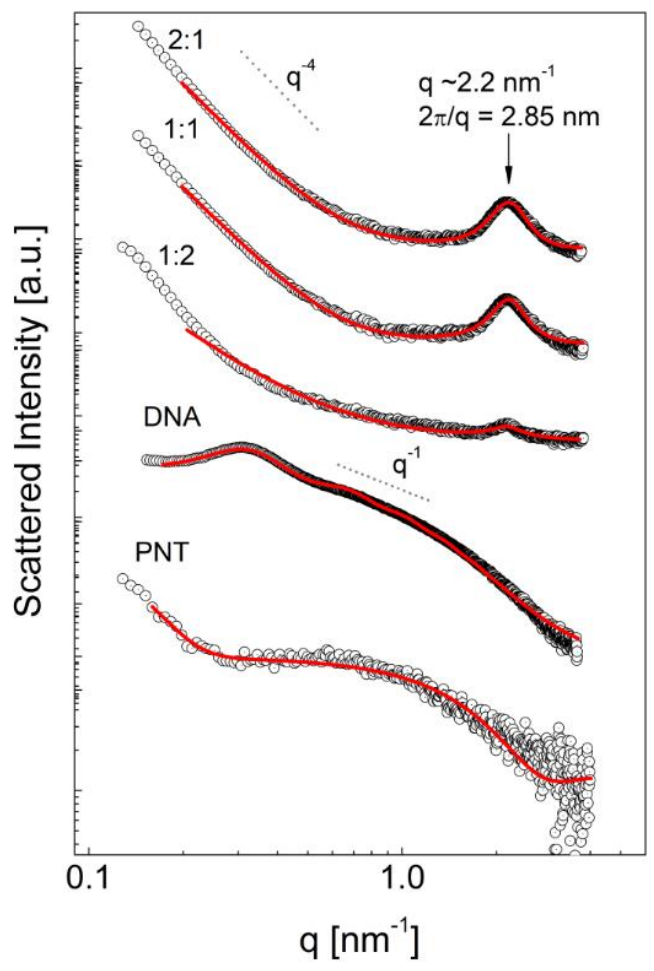

Figure 1: SAXS data from solutions containing Penetratin (PNT), DNA and PNT/DNA complexes at the molar charge ratios $\left(\mathrm{N}^{+}: \mathrm{P}^{-}\right)$indicated. Scattering from PNT/DNA formulations (upper curves) cannot be described in terms of linear combinations of their single-phase components, which is ascribed to appearance of new polymorphs upon complexation. The presence of Bragg peaks indicates the formation of ordered domains in the inner structure of the complexes. Solid red lines correspond to model fitting through least-square approaches discussed in the text.

Figure 1 presents SAXS curves from either single-component solutions (i.e., containing only $P N T$ or double-stranded DNA) or mixtures containing PNT/DNA complexes at peptide-toDNA charge ratios $\mathrm{N}^{+}: \mathrm{P}^{-}=2: 1,1: 1$ and 1:2. A first qualitative assessment reveals that scattering profiles from PNT/DNA samples (upper curves in Fig. 1) are not described in terms of linear combinations of their single-phase constituents. Scattering profiles of two-component systems can be described by linear combinations of their single components when shapes found in the original solutions are kept upon mixing ${ }^{38}$ and inter-particle interactions are not at play in bimodal systems. ${ }^{39}$ As further demonstrated either by SAXS data or by microscopy images herein, these scattering profiles that are not described in terms of single-phase components indicate that new polymorphs appear upon complexation between PNT and DNA. In the upper curves of Figure 1, the appearance of Bragg peaks at $\mathrm{q} \sim 2.2 \mathrm{~nm}^{-1}$ is an obvious feature indicating that new structural 
levels are present in the mixtures. In fact, data from solutions containing PNT/DNA assemblies show scaling law behaviors at low- $q$ range and the strong interference peak at high $q$-values attests the presence of fractal aggregates with a distinctive internal correlation distance. The exponents of these scaling laws provide information on dimensionality of fractal aggregates. ${ }^{38}$ Curves from PNT samples (lower curve, Fig. 1) are characterized by a large plateau at intermediate- $q$ range, followed by a steepest descent at high-angles scaling with $\sim q^{-1.5}$. This result is analogous to the scattering from polymer Gaussian chains and it is consistent with partially-coiled peptide strands in solution. ${ }^{28,40}$ At low $q$, SAXS data for PNT show an upturn in intensity, indicating co-existence of larger aggregates in the solutions. These data were properly fitted using a combination of the generalized Gaussian coil model and the Fisher-Burford fractal model ${ }^{28,38}$ (further details on the model may be found in the SI file, Eqs. S1 and S2, and Fig. S3). The fitting procedure allowed us to determine structural parameters of the particles, including their gyration radius $\left(R_{g}\right)$, the Flory exponent for peptide chains $(v)$ and the fractal dimensionality of larger aggregates in solution $(D)$. The radius of gyration of Gaussian chains is $R_{g}=1.4 \mathrm{~nm} \pm 0.2$, whereas the Flory exponent was found to be $v=0.5$. These values are consistent with peptide strands in a theta solvent. ${ }^{38,39}$ The fitted fractal component has $R_{g}=14.2 \pm 1.0 \mathrm{~nm}$ and fractal dimensionality $D=2.5 \pm 0.1$, indicating the presence of surface fractal aggregates with rough interfaces. As a whole, the fitting proved the co-existence of $P N T$ monomers in a theta solvent with fractal oligomeric aggregates.

Curves from DNA solutions are characterized by a power law descent scaling with $\sim q^{-1}$, consistent with rod like-structures. An interference peak is noticed at $q \sim 0.3 \mathrm{~nm}^{-1}$, which is a consequence of positional order arising from repelling (negatively-charged) DNA chains. To fit the data, we have used a cylinder shell form factor convoluted with the PRISM structure factor. $^{41,42}$ Further details on the model are given in the SI file (Eqs. S3-S7, Fig. S4). The radius of the cylinder core was fitted at $R_{c}=0.8 \pm 0.4 \mathrm{~nm}$ whereas the thickness of the shell was found to be $\Delta S=0.5 \pm 0.4 \mathrm{~nm}$. These values are in close agreement with reported values for DNA strands, with bases and phosphate groups forming the core of duplexes surrounded by a shell of hydration and counterion layers. ${ }^{32,43}$ The cross-section radius $\left(\mathrm{R}_{\mathrm{CS}}\right)$ due to electrostatic repulsion 
between DNA chains was found to be $R_{C S}=8.4 \pm 1.1 \mathrm{~nm}$, revealing average separation of about $16.8 \mathrm{~nm}$ between chains, in close agreement with previous data on calf thymus DNA solutions. ${ }^{44}$

In the case of $P N T / \mathrm{DNA}$ complexes, the shape of the SAXS profiles is quite different and data exhibit multiple structural levels across the $q$-range investigated. By inspecting upper curves in Figure 1, we find out that the low $q$ range is characterized by a power law decay scaling with exponents close to -4 . This behavior is consistent with the Porod law for smooth surfaces ${ }^{38}$ and it indicates the presence of structures bigger than lengths resolvable by our SAXS experiments, $50 \mathrm{~nm}$. The interference peak at $q \sim 2.2 \mathrm{~nm}^{-1}$ (Figure 1) indicates a repeat distance of $2 \pi / q \sim 2.9$ $\mathrm{nm}$, which is larger than the diameter of DNA double strands $(\sim 2 \mathrm{~nm})$. Interestingly, we observe that charge ratio affects the scattering profiles. Indeed, for $\mathrm{N}^{+}: \mathrm{P}^{-}=1: 2$, the slope of the intermediate $q$-range approaches -1 and the interference peak carrying information on correlated domains is less pronounced, suggesting the presence of rod-like particles (DNA chains) and lower compactness of the inner structure due to smaller content of cationic charges. Unfortunately, it is not easy to conceive an analytical model that accounts for all structural features found in the SAXS data from PNT/DNA complexes. In this case, we have adopted an empirical approach based on the summation of a power-law and a broad peak function ${ }^{45}$ (see SI file, Eqs. S8 and $S 9$ ). This model has been successfully used to describe scattering data with multiple structural levels from other soft matter systems ${ }^{38,46}$ and it allows for quantifying shape-independent parameters such as dimensionality of fractal structures and correlation lengths $(\xi)$ associated to interference peaks (see best fitting parameters in Table $\mathrm{S} 1$, SI file). The fitting procedure indicated that $\mathrm{N}^{+}: \mathrm{P}^{-}$ $=1: 2$ sample is populated by mass-fractal aggregates with dimensionality $D_{m}=2.1$, which is consistent with highly interconnected networks.[38] The center of the interference peak is located at $q_{0}=2.16 \mathrm{~nm}^{-1}$, whereas the correlation length is found at $\xi=3.16 \mathrm{~nm}$ indicating short-range ordering of scattering inhomogeneities, and suggesting structures with a low degree of order. In the case of formulations with $\mathrm{N}^{+}: \mathrm{P}^{-}=1: 1$ or $2: 1$, power-law exponents increase, and the aggregates are classified as surface-fractals (see details in the SI file, Eq. S9). Fractal dimensionalities are found at $D_{s}=2.3$ and 2.6, respectively, for compositions with 1:1 and 2:1 charge molar ratio. Peak 
positions are found at $q_{0}=2.19 \mathrm{~nm}^{-1}$ for both formulations and correlation lengths are determined at $\xi=3.54$ and $3.23 \mathrm{~nm}$, respectively. The parameter $D_{s}$ carries information on the smoothness of the interfaces of aggregates in solution. $D_{s}=2$ represents perfectly smooth surfaces, whereas values approaching 3 correspond to "very rough" surfaces ${ }^{47}$ The correlation length, $\xi$, is related to the degree of order between adjacent structures in the inner part of aggregates, and it reaches a maximum for $\mathrm{N}^{+}: \mathrm{P}^{-}=1: 1$. Putting the findings above together, our data indicate that the formulation with molar equivalence between charges produces self-assemblies with the smoothest interfaces with the solvent and the highest degree of internal ordering. Therefore, these aggregates also show the highest compactness among those investigated here, which is consistent with total complexation at this composition and absence of exceeding PNT or DNA. Complementary neutron scattering experiments probed the intermediate $q$-range either in PNT/DNA complexes or in single-phase (PNT or DNA) solutions (see SI file, Fig. S6). The results found in these assays were consistent with SAXS measurements, confirming the robustness of the structural information derived above.

\section{Secondary structure: FTIR and CD in solution}

FTIR assays were carried out to provide insights into chemical groups playing a role for complexation between peptide and DNA, and to investigate the secondary structure of PNT upon association with nucleic acids. By probing the vibrational spectra of the samples, we have been able to get insights into chemical groups affected by association between PNT and DNA and extract information on the chemical moieties implied in the formation of the complexes. Solutions used for FTIR experiments were prepared at different charge ratios, using deuterated water as a solvent. Two major regions of the infrared spectrum were scanned in these experiments, the sugarphosphate region and the amide I band. The first range comprises wavenumbers situated between 1000 and $1300 \mathrm{~cm}^{-1}$ and it carries information on chemical bonds of phosphate and ribose groups. The second region comprises the amide I band located between 1600 and $1700 \mathrm{~cm}^{-1}$, exhibiting resonances related to $\mathrm{NH}$ moieties on peptide backbones. ${ }^{48}$ Vibrations related to DNA guanine 
groups could be found in the range $1700-1800 \mathrm{~cm}^{-1} \cdot{ }^{46,47}$ Data from sugar-phosphate region are shown in Figure 2A and they reveal that complexation between $P N T$ and nucleic acids strongly affects vibrations related to chemical groups on the DNA backbone. Particularly, bands are noticed at 1010 and $1023 \mathrm{~cm}^{-1}$, being assigned to ester phosphate/ribose linkage. ${ }^{49,50}$ These peaks appear accompanied by strong resonances at 1054 and $1084 \mathrm{~cm}^{-1}$, which are ascribed to stretching of $\mathrm{C}-\mathrm{O}$ bonds at deoxyribose and stretching of $-\mathrm{PO}^{2-}$ groups, respectively. By comparing these bands with peptide-free solutions, one observes increasing intensity and sharpness in complexes containing PNT at charge ratios closer to the neutralized charge. On the other hand, these bands are found to decrease in mixtures where cationic charges overpass the number of anionic groups. Unfortunately, we are not able to devise here a rigorous explanation for this effect, but we hypothesize it is related to electrostatic perturbation taking place upon conjugation of species with different charges. ${ }^{46,48}$ In fact, in PNT/DNA samples, strong polyelectrolytes are in involved in the formation of complexes. DNA is the strongest polyanion found in nature ${ }^{33}$ and small fractions of nucleic acid strands likely have a dramatic influence on the interplay between charges in Penetratin chains. In this case, we propose that the presence of opposite charges affects dipolar moments associated to chemical bonds contributing to the infrared spectra, similar to what is observed for DNA structure in presence of ionic species. ${ }^{46,48}$ When there is an excess of cationic charges, there appears to be a reduction of dipole moments and, closer to neutrality, they are reinforced.

A very intense peak at $1198 \mathrm{~cm}^{-1}$ is noticed either for samples containing DNA or for solutions prepared exclusively with $P N T$; in this case, we have assigned it to scissoring bend of $\mathrm{D}_{2} \mathrm{O}$ molecules ${ }^{51}$ and used it as an internal standard for normalizing absorbance intensities. A shallow shoulder at $\sim 1230 \mathrm{~cm}^{-1}$ is also noticed only in samples close to the neutral charge point and it is tentatively ascribed to antisymmetric stretching of $-\mathrm{PO}^{2-}$ and its reinforcement in complexes closer to neutral charge point corroborates the role of phosphate groups as key mediators of complexation. In previous studies have demonstrated that association between arginine-rich peptides and nucleic acid sequences is strongly influenced by interactions between 
guanidinium moieties and phosphates. ${ }^{52,53}$ In this case, in addition to the strong Coulomb attraction between these species, the formation of bidentate H-bonds by arginine sidechains has been observed ${ }^{52}$ and all these features together have strong repercussion in the vibrational behavior of phosphate stretching.
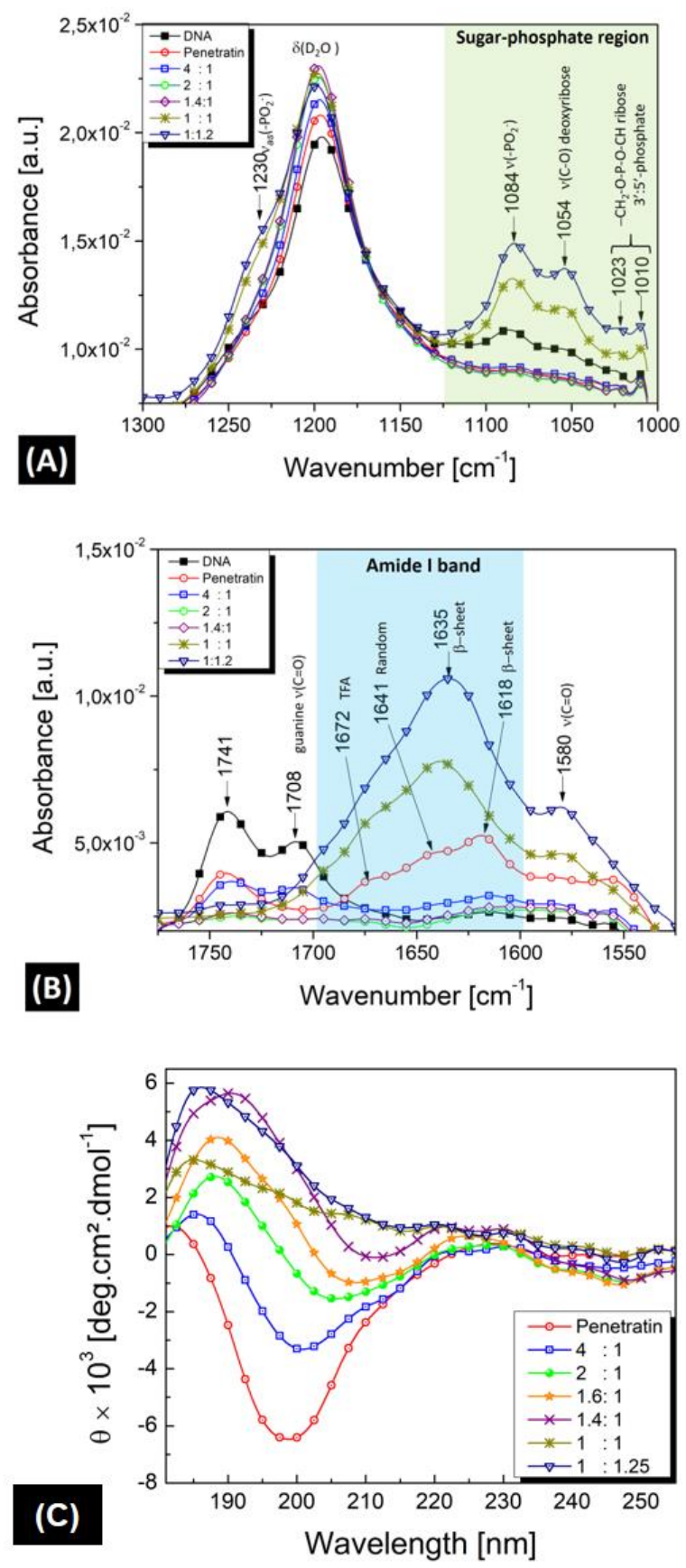

Figure 2: Spectroscopy assays from solutions containing PNT and DNA at the charge ratios indicated. (A) and (B) FTIR data collected across spectral ranges corresponding to DNA sugarphosphate region and peptide amide band, respectively. (C) CD data from DNA titration into PNT solutions. 
Figure 2B shows infrared data across the amide I region. Similar to the behavior observed in the sugar-phosphate region, solutions containing complexes closer to the neutral charge point exhibit spectra with peaks with increased intensity and sharpness, whereas those with exceeding cationic charges show a diminution of their vibrations. Again, this observation is interpreted as an indication for changes of dipole moments due to the electrostatic interactions arising from presence of charged groups in the surroundings and, since the vibrations are associated to secondary structure of peptides, they may also suggest appearance of new conformers upon complexation with DNA. These samples are characterized by a strong peak centered at $1635 \mathrm{~cm}^{-}$ ${ }^{1}$, which is assigned to the presence of $\beta$-sheet fractions increasing when peptide strands condense onto the backbone of DNA duplexes. Since this band is broad, disordered structures likely contribute to the infrared profile. Spectra from $P N T$ solutions feature peaks at 1618 and $1641 \mathrm{~cm}^{-}$ 1, which are ascribed, respectively, to $\beta$-sheet and random coil content in the sample. ${ }^{54,55}$ Since SAXS data from $P N T$ solutions prepared at the same concentrations used in FTIR assays indicated coexistence of coiled peptide strands and small aggregates in solution, we propose that the $\beta$-content observed in FTIR is related to oligomeric peptide aggregates whereas disordered conformations are likely associated to free PNT strands. Data from DNA solutions exhibit peaks at 1708 and $1741 \mathrm{~cm}^{-1}$ which are associated to $\mathrm{C}=\mathrm{O}$ stretching. Particularly, the band at $1708 \mathrm{~cm}^{-}$ ${ }^{1}$ has been ascribed to guanine $\mathrm{C}=\mathrm{O}$ bonds. ${ }^{49}$

Assessment of the secondary structure of complexes was independently probed by circular dichroism (CD) and the findings revealed by FTIR qualitatively agree with information derived from CD assays. In Figure 2C, CD spectra from PNT show that its secondary structure is dominated by random coil conformations, as attested by a remarkable negative peak at $198 \mathrm{~nm}$, and in agreement with previous literature. ${ }^{11}$ Interestingly, upon titration of lower amounts DNA, a positive peak appears close to $190 \mathrm{~nm}$ along with a negative peak at $\sim 210 \mathrm{~nm}$, corresponding to blue-shifted $\beta$-sheet spectra. The spectra become gradually dominated by DNA features and CD also shows that the DNA loses its helical structure, as it can be seen by the decrease in the 
maxima/minima ratio in the spectra. In this case, it becomes harder to discriminate conformational features of peptide strands when larger amounts of DNA are present in the samples. Linear combinations of $P N T$ and DNA components were not capable of fitting the experimental data, confirming that new secondary structures appear upon complexation (Figure S4, SI file). The presence of more than one isochroic point in the data indicates that more than two states are present in the solutions and the random-to- $\beta$ transition occurs in a context of reduced cooperativity. ${ }^{56}$

The findings above can be compared to membrane-mediated transitions observed in PNT chains interacting with DOPC/DOPG vesicles. ${ }^{11,57,58}$ In this case, a nucleation-dependent mechanism has been proposed to explain the formation of $\beta$-sheet oligomers from random-coiled monomers. ${ }^{57}$ The data presented above demonstrate that DNA is also to mediate a similar transition, thus suggesting that a nucleation mechanism can be used for explaining $\beta$-sheet pairing. Indeed, negative charges at DNA backbones likely promote electrostatic attraction between $P N T$ chains leading to condensation of peptide strands. In this context of strong confinement, where repulsive forces between cationic amino acid residues are also screened by anionic charges in their surroundings, lateral association into paired $\beta$-sheets should be assisted.

\section{AFM-IR: infrared data from individual complexes}

The secondary structure of individual PNT/pEGFP-N3 complexes has been examined using infrared nanospectroscopy. This is a powerful technique, combining atomic force microscopy and infrared spectroscopy (AFM-IR), which provides information on chemical bonding with nanoscale spatial resolution. ${ }^{35,36}$ By using the AFM-IR technique, we have been able to measure the vibrational profile of individual peptide assemblies at resolutions of about 30 $\mathrm{nm}$ to provide infrared absorbance maps. ${ }^{53}$ One of the advantages of this approach is that it provides single-particle spectra, in contrast to average information obtained in FTIR measurements performed in bulk solutions. In Figure 3A, a topography image shows assemblies 
dried from a mixture containing $P N T$ and pEGFP-N3 at charge molar ratio $\mathrm{N}^{+}: \mathrm{P}^{-}=1: 1$. The particles are characterized by irregular shapes and polydisperse sizes, with lateral dimensions ranging from hundreds of nanometers to bigger coalesced aggregates in the micrometer range. The heights of aggregates remain in the range from tens to few hundreds of nanometers (see SI file, Figure S6). Since tip width limits the area for infrared information to a circle with diameter $\sim 30 \mathrm{~nm}$, we have chosen bigger aggregates in the sample to collect the data. In Figure 3B, spectra registered on the top of six individual assemblies are presented along with their average (black curve). The colors of the curves allow identifying the corresponding particle used for data collection (see colored spots in 3A). Although spectra from dried aggregates exhibit a different outlook compared to infrared data from hydrated samples, they also indicate secondary structure is composed by large fractions of $\beta$-content alongside with random coil conformations. Changes on infrared signatures are likely a consequence of rearrangements due to dehydration, similar to what is observed in proteins. ${ }^{59}$ Remarkable vibrations appear near to $1645 \mathrm{~cm}^{-1}$, which is assigned to disordered structures. ${ }^{55,59}$ Bands around $1673 \mathrm{~cm}^{-1}$ are noticed in all spectra and they could indicate either $\beta$-turns or originate from TFA salt in the medium. ${ }^{29}$ Also, this vibration is consistent with $\mathrm{C}=\mathrm{N}$ anti-symmetric stretching in arginine guanidium groups $;{ }^{55}$ however, the presence of shoulders at $\sim 1690 \mathrm{~cm}^{-1}$ indicates the presence $\beta$-turns or even anti-parallel $\beta$-sheets corroborating the presence of $\beta$-content in the aggregates. Noteworthy is that spectra from different aggregates show subtle differences indicating variations on the secondary structure; although peak positions exhibit approximately the same pattern across amide I band, intensities are found to change, and it could be an indication that fractions of $\beta$-content and disordered structures are different depending on the aggregate investigated. 

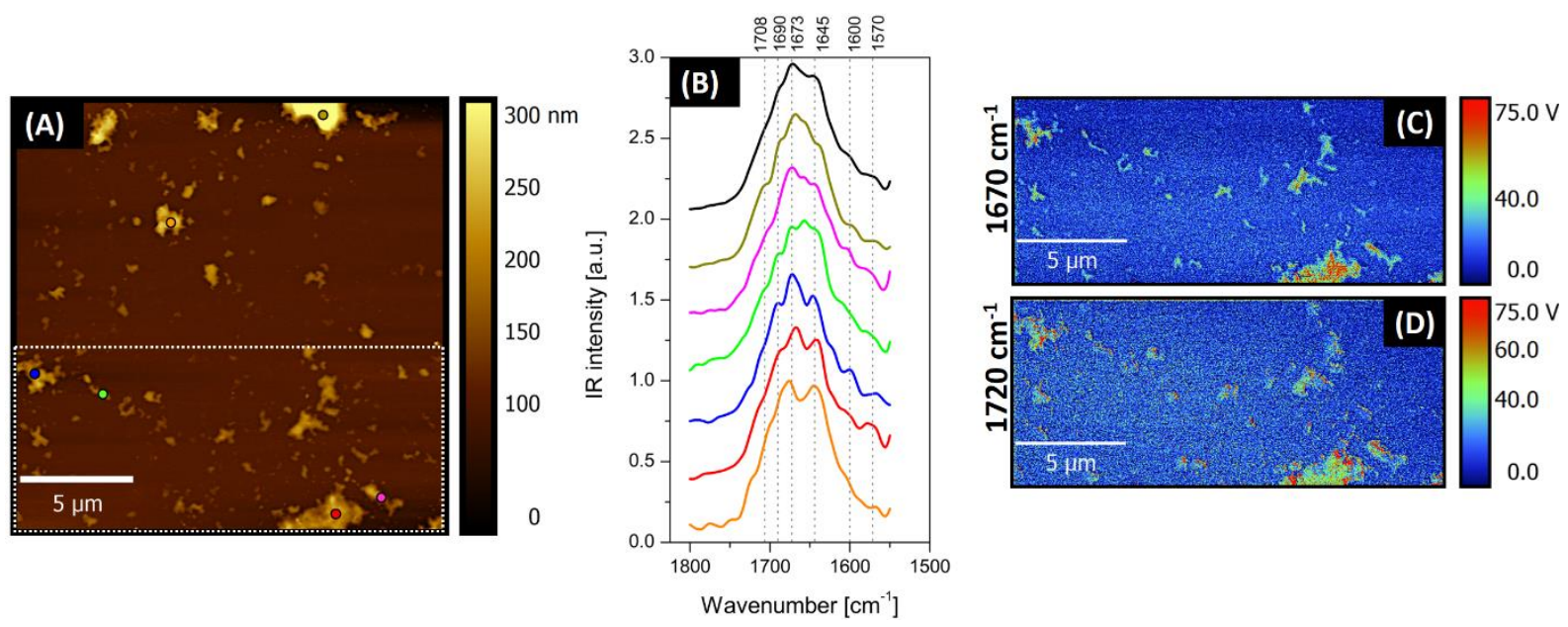

Figure 3: AFM imaging combined with infrared nanospectroscopy. (A) Topography from complexes formed between pEGFP-N3 and PNT at 1:1 $\mathrm{N}^{+}: \mathrm{P}^{-}$ratio; (B) infrared spectra from individual particles. The color of each spectrum corresponds to the color of the spot on the top of the particle indicated in (A); (C) and (D) chemical maps showing the spatially-resolved absorbance, respectively, at $1670 \mathrm{~cm}^{-1}$ and $1720 \mathrm{~cm}^{-1}$. The region used for infrared mapping is indicated by a dashed area in the topography image (A).

The nanospectroscopy technique was also used to obtain chemical images from PNT/ pEGFP-N3 complexes. Absorbance maps shown in Figures 3C and D were collected at 1670 and $1720 \mathrm{~cm}^{-1}$, wavenumbers respectively associated to vibrations from the amide I region and guanine base. ${ }^{49,50}$ Since there are several chemical groups and two components in the mixture, a straightforward interpretation of the data is not possible; however, comparison between absorbance distributions at these wavenumbers could provide insights into the localization of peptide-enriched domains. The maps reveal that absorbances associated to the different wavenumbers are not homogeneously distributed in the particles, suggesting that different chemical compositions are found across the complexes. In fact, one observes that the signal at $1670 \mathrm{~cm}^{-1}$ (amide I band) is stronger in the central region of the assemblies, whereas signal at $1720 \mathrm{~cm}^{-1}$ is complementarily enhanced near to their borders (see SI file, Fig. S5 for a difference map). In this case, we propose that core of the complexes is enriched in PNT whereas the periphery exhibits larger fractions of DNA. Indeed, these findings are consistent with the amphipathic design of $P N T$ peptides, which contains hydrophobic amino acids likely able to form 
lipophilic domains in the inner part of aggregates. On the other hand, DNA is a very water-soluble molecule and its affinity to interfaces with the aqueous solvent should be favored. The formation of peptide-enriched cores is also consistent with recent findings that revealed self-association between arginine-rich sequences, including the Tat-HIV peptide. ${ }^{60,61}$ In this case, capabilities of guanidinium moieties to form bidentate H-bonds play a paramount role for association and attractive forces arising from anisotropic charge distribution in like-charged groups assist the assembly of peptide strands.

\section{Transmission electron microscopy visualization}

Transmission electron microscopy (TEM) imaging was carried out to provide directspace visualization of complexes formed between $P N T$ and DNA fragments. These experiments yielded information on the morphology and sizes of self-assemblies, allowing for comparison with SAXS and AFM data presented above. Samples were formulated with molar equivalence between positive and negative charges, and TEM grids were prepared from solutions containing peptides at $0.1 \mathrm{mg} / \mathrm{ml}$. Micrographs shown in Figure 4 confirm complexation between peptides and DNA and they reveal the formation of discrete nanostructures with sizes ranging from a few nanometers up to hundreds of nanometers. Interestingly, TEM images from preparations containing only the Penetratin peptide at the same concentration used to formulate complexes do not indicate the formation of ordered assemblies and amorphous films are found throughout the grids (see SI file, Fig. S11). The absence of discrete nanostructures is likely ascribed to the strong cationic nature of the peptide since association between Penetratin chains is presumably hindered by electrostatic repulsion. In this case, we have here evidence that negatively-charged DNA strands behave as a structuring agent for Penetratin by screening electrostatic charges and enabling the formation of supramolecular arrangements. Both globular aggregates and fibrillar structures are found throughout the samples (see Figs. 4A and B) and association between globules connected by thread-like structures (see Fig. 4C) often leads to beads-on-a-string or "bunch of grapes" morphologies (Figs. 4D and E) rather resembling chromatin. ${ }^{55}$ The thicknesses 
of these fibers are in the range of 7-10 nm, which is much higher than the diameter of DNA duplexes, indicating that they are likely composed of nucleic acid strands wrapped by peptide shells (see discussion on the sketch represented in Figure 5 below). In light of these findings, we propose that such peptide-wrapped strands correspond to the starting units of the self-assembly pathway leading to the formation of more complex structures at higher scales. In this case, association between adjacent fibers through fusion of peptide shells could lead to appearance of peptide-enriched domains in the inner part of the larger aggregates, in agreement with nanospectroscopic information derived from absorbance maps revealed by AFM-IR (see Figs. 3C above and SI file S9). The globular units observed in TEM images exhibit average size at c.a. 47 $\mathrm{nm}$, with dimensions up to $75 \mathrm{~nm}$. These values are also in agreement with the persistence length of DNA chains and with the average size of DNA fragments used to formulate the complexes (200 bp or $\sim 68 \mathrm{~nm}$ ).
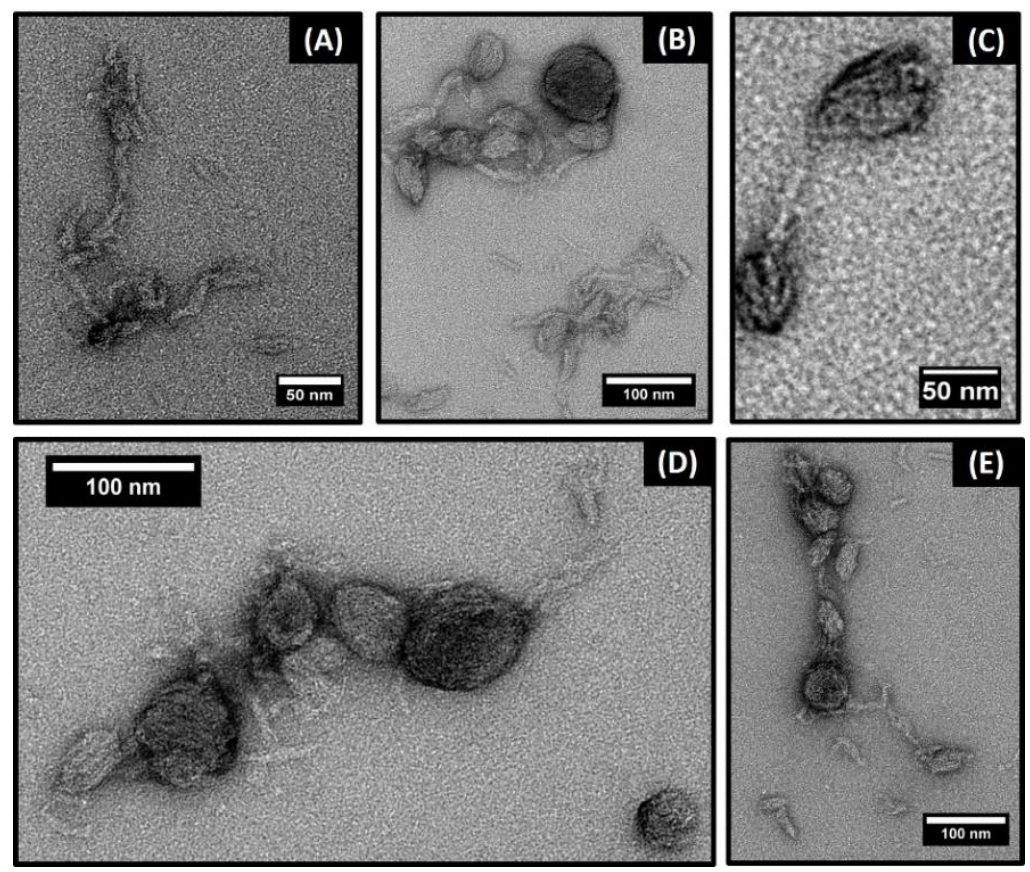

Figure 4: TEM micrographs from complexes formed between $P N T$ and DNA fragments at molar charge ratio 1:1. Coexistence between fibrillar assemblies and globular aggregates, and association between globules connected by thread-like structures is found throughout the samples. 


\section{Complexation pathway}

The results presented above reveal that the structure of PNT/DNA conjugates is intricate and different polymorphs are found in the samples. In spite of this complexity, TEM and AFM imaging, alongside with SAXS and spectroscopic information, provide several insights into the organization of these systems, from secondary structure to the micrometer range, and enable us to draft a pathway for the structuring process of the conjugates. In addition, the data allow to hypothesize that a hierarchical framework is at play in the self-assembly and polymorphs appear at different size scales where larger structures seem to be composed of subunits visualized in the samples.

Our proposition is divided into five major steps and it appears sketched in Figure 5. According to this model, complexation is triggered by electrostatic attraction between negative charges at DNA phosphates and cationic groups at peptide chains. In Step 1, initial supramolecular association is represented by nucleic acid duplexes decorated with Penetratin chains. The role of electrostatic forces as a major self-assembling force is supported by FTIR information that suggests increase of dipole moment in phosphate diester bonds when DNA is cosolubilized with Penetratin, an effect which is likely ascribed to the presence of opposite charges in the vicinities of these groups. In Step 2, the formation of fibrillar arrangements composed of DNA cores wrapped by peptide shells is illustrated, resembling electron microscopy images that shows the presence of rod-like arrays with diameters in the range of 7-10 nm (see Figure 4 and SI file). This step is crucial for further stages of self-assembly because these fibrils correspond to subunits found in the composition of larger aggregates.

In Step 3, the formation of highly packed condensates is initiated by lateral association of core-shell fibers through fusion of Peneratin layers. At this stage, sizes of condensates are usually found to be around $50 \mathrm{~nm}$, limited by the persistence length of DNA chains. Fusion is easily observed in TEM images and thread-like assemblies are visible in micrographs exemplifying Step 
3 in Figure 5, and in Figures 4A and S12 (SI file). In addition, micrographs reveal that threads are often connected to globules, indicating that fibrils are in fact subunits composing these round aggregates and they should play a role in tethering globular structures. In fact, the presence of globular assemblies connected by thread-like arrays is abundant and may be identified in micrographs shown in Figures 4C, 4D and additional images in SI file. Step 4 is characterized by coalescence of globules into larger bunch-like structures and aggregates now scale up to a few hundreds of nanometers.

Finally, Step 5shows coalescence aggregates in the micrometer range leading to particles with irregular shape because of unspecific association between globules and fiber-like subunits. To reconciliate the findings above with infrared nanospectroscopy information, which evidenced the presence of peptide-rich domains in the core of the assemblies and DNA content in the periphery of aggregates, we propose that coalescence is accompanied by a rearrangement of the inner structure. This reorganization is driven mainly by interactions related to amphiphilicity of the biomolecules. Indeed, since Penetratin contains an appreciable number of nonpolar groups along its composition, hydrophobic effect could push the peptide inward the assemblies, whereas the high hydrophilicity of double-helix phosphates would compel DNA toward the interfaces with water. 


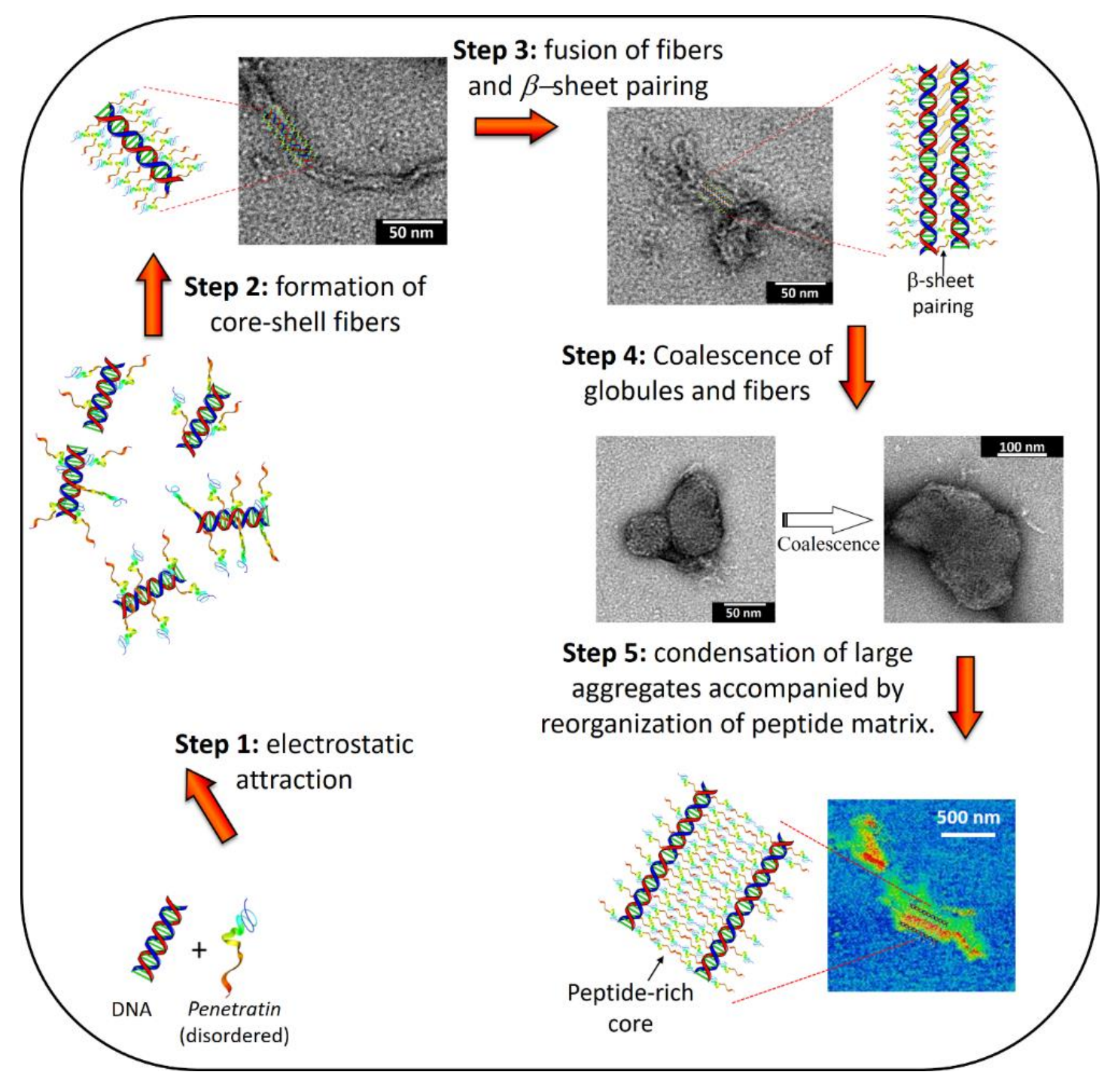

Figure 5: Schematic representation of the proposed pathway for PNT/DNA complexation. Selfassembly is divided into five major steps, from biomolecular association up to the micrometer range. Different polymorphs are visualized across the samples and hierarchical aggregation, where $P N T / D N A$ fibers behave as subunits within higher scale arrangements, is identified.

\section{CONCLUSIONS}

We have conducted detailed investigations on the structure of complexes formed between DNA and the PNT cell penetrating peptide. A combination of in-situ and ex-situ techniques provided an accurate characterization of supramolecular assemblies throughout a wide range of lengths, from the secondary structure up to the nanometer scale. Several polymorphs have been identified with assistance of different techniques, and coexistence of fibrillar, globular and 
coalesced assemblies has been unequivocally demonstrated. Morphology of aggregates has been found to exhibit fractal-like features, and sizes were found to cover from nanometer to micrometer range. In addition, the inner structure has been found to comprise domains with short-range order and secondary structure has been found to be predominantly $\beta$-sheet, alongside disordered conformations. Complexation involves spontaneous formation of core-shell assemblies, with PNT shells condensing around nucleic acid strands, and this stage is likely followed by collapsing of fibrillar structures into globular cores where fusion between peptide shells leads to highly compacted scaffolds. FTIR assays carried out in solutions containing PNT/DNA complexes show that electrostatic interactions are mediated by phosphate groups along DNA backbone and both $\mathrm{PO}^{2-}$ moieties and ester linkages are strongly affected upon complexation, probably due to charge delocalization induced by the proximity of positive charge from amine groups present at peptide side-chains. Not surprisingly, the strong cationic nature of PNT makes it a very efficient agent for condensing DNA duplexes via electrostatic attraction; however, our study has demonstrated that condensation is accompanied by DNA-mediated random-to- $\beta$-sheet transitions of peptide secondary structure and a comparison with previous studies on charged lipid membranes suggests that a nucleation mechanism could be at the origin of this effect. ${ }^{11,57,58}$ In this case, nucleic acids behave as a structuring agent for the peptide and, to our knowledge, this is the first time that such a DNA-induced transitions have been probed in $P N T$ complexes. These findings indicate that, although electrostatic attraction is the underlying force triggering complexation, the role played by nonpolar residues in the resulting organization of $P N T /$ DNA complexes should not be underestimated. For instance, our study revealed extensive presence of $\beta$-sheet peptide assemblies which likely results from the interplay of hydrophobic interactions in the core of the assemblies.

Importantly, we have used a cutting-edge technique, AFM combined with nanospectroscopy, to collect single-particle vibrational information and provide nanoscale resolved maps of infrared absorbance across the self-assemblies. As far as we know, this was the first time that complexes formed between DNA and CPPs were investigated in this way. These 
assays confirmed predominance of $\beta$-sheet structures and random coil conformations in the complexes and indicated variations in the fractions of secondary structure components between different aggregates. Infrared absorbance maps revealed domains enriched in $\beta$-structures in the core of the complexes and regions exhibiting stronger vibrations associated to DNA bases concentrated closer to the borders of the assemblies. These findings suggest some degree of spatial separation between DNA and Penetratin in the complexes and they indicate that the nucleic acid load in these carriers tend to be located closer to the interfaces with the surrounding medium. This information is a very interesting contribution of the present study because it could explain why PNT/DNA conjugates formulated via noncovalent approaches usually show lower transfection efficiencies in comparison to complexes obtained from covalent linkage of nucleic acid sequences to Penetratin oligomers. ${ }^{3,56}$ In fact, since our data suggest that DNA is predominantly located in the periphery of the complexes; thus, protection of the load and interaction with cell membranes are likely depressed in these species.

Analyses conducted here probably could be carried out for complexes involving DNA and other CPPs, but sequence-specific features likely should appear. Such structural differences presumably play a role for internalization pathways, delivery efficiency, load capacity and other variables that appear upon interaction with cells. All these features together highlight the importance of knowing the nanoscale structure of these complexes in detail since it could be considered for efficient design of nucleic acid carriers based on CPPs.

\section{SUPPORTING INFORMATION}

Gel electrophoresis assays, peptide characterization, SAXS modeling, SANS data, additional AFM-IR and TEM images.

\section{ACKNOWLEDGMENTS}

This work was supported by FAPESP under project n 2016/24409-3 (granted to ERS) and 2015/20206-8 (to SHW). ERS is recipient of a CNPq fellowship $\mathrm{n}^{\circ}$ 307017/2016-8. LRM is 
recipient of a CAPES fellowship of the Graduate Program in Molecular Biology of UNIFESP. IWH is grateful to EPSRC (UK) for a Platform Grant (ref. EP/L020599/1). This project was partially supported by the UNIFESP CAPES-PrInt program. CLPO is recipient of a CNPq fellowship n ${ }^{\circ} 304861 / 2015-4$. SAXS data were collected at LNLS under proposals $n^{\circ} 20170958$ and 20190106 and at ESRF under proposal ${ }^{\circ}$ SC-4739. SANS experiments were carried out on ISIS-LOQ beamline (proposal 1810004), and we thank James Doutch for assistance. Carlos Costa and Evandro Manzoni are acknowledged for help and discussions during AFM experiments at LNNano (proposal n : AFM21086 and AFM22077). TEM data were collected at LNNano under proposal $\mathrm{n}^{\circ}$ : TEM-23419. Prof. Juliana dos Santos de Souza (at UFABC) is kindly acknowledged for providing access to FTIR instrument. We thank Rogerio Lauria and Prof. Antonio Miranda (Biophysics dept, UNIFESP) for LC-MS characterization.

\section{REFERENCES}

(1) Guidotti, G.; Brambilla, L.; Rossi, D. Cell-Penetrating Peptides: From Basic Research to Clinics. Trends Pharmacol. Sci. 2017, 38 (4), 406-424.

(2) Copolovici, D. M.; Langel, K.; Eriste, E.; Langel, U. Cell-Penetrating Peptides: Design, Synthesis, and Applications. ACS Nano 2014, 8 (3), 1972-1994.

(3) Kurrikoff, K.; Gestin, M.; Langel, U. Recent in Vivo Advances in Cell-Penetrating Peptide-Assisted Drug Delivery. Expert Opin. Drug Deliv. 2016, 13 (3), 373-387.

(4) Kalafatovic, D.; Giralt, E. Cell-Penetrating Peptides: Design Strategies beyond Primary Structure and Amphipathicity. MOLECULES 2017, 22 (11).

(5) Agrawal, P.; Bhalla, S.; Usmani, S. S.; Singh, S.; Chaudhary, K.; Raghava, G. P. S.; Gautam, A. CPPsite 2.0: A Repository of Experimentally Validated Cell-Penetrating Peptides. Nucleic Acids Res. 2016, 44 (D1), D1098-D1103.

(6) Kauffman, W. B.; Fuselier, T.; He, J.; Wimley, W. C. Mechanism Matters: A Taxonomy of Cell Penetrating Peptides. Trends Biochem. Sci. 2015, 40 (12), 749-764.

(7) Herce, H. D.; Garcia, A. E.; Litt, J.; Kane, R. S.; Martin, P.; Enrique, N.; Rebolledo, A.; Milesi, V. Arginine-Rich Peptides Destabilize the Plasma Membrane, Consistent with a Pore Formation Translocation Mechanism of Cell-Penetrating Peptides. Biophys. J. 2009, 97 (7), 1917-1925.

(8) Milletti, F. Cell-Penetrating Peptides: Classes, Origin, and Current Landscape. Drug Discov. Today 2012, 17 (15-16), 850-860.

(9) Bechara, C.; Sagan, S. Cell-Penetrating Peptides: 20 Years Later, Where Do We Stand? Febs Lett. 2013, 587 (12), 1693-1702.

(10) Hu, Y. X.; Haynes, M. T.; Wang, Y. H.; Liu, F.; Huang, L. A Highly Efficient Synthetic 
Vector: Nonhydrodynamic Delivery of DNA to Hepatocyte Nuclei in Vivo. ACS Nano 2013, 7 (6), 5376-5384.

(11) Eiríksdóttir, E.; Konate, K.; Langel, Ü.; Divita, G.; Deshayes, S. Secondary Structure of Cell-Penetrating Peptides Controls Membrane Interaction and Insertion. Biochim. Biophys. Acta - Biomembr. 2010, 1798 (6), 1119-1128.

(12) Joliot, A.; Pernelle, C.; Deagostini-Bazin, H.; Prochiantz, A. Antennapedia Homeobox Peptide Regulates Neural Morphogenesis. Proc. Natl. Acad. Sci. 1991, 88 (5), 18641868.

(13) Derossi, D.; Calvet, S.; Trembleau, A.; Brunissen, A.; Chassaing, G.; Prochiantz, A. Cell Internalization of the Third Helix of the Antennapedia Homeodomain Is ReceptorIndependent. J. Biol. Chem. 1996, 271 (30), 18188-18193.

(14) Vives, E. Present and Future of Cell-Penetrating Peptide Mediated Delivery Systems: "Is the Trojan Horse Too Wild to Go Only to Troy?" J Control Release 2005, 109 (1-3), $77-85$.

(15) Futaki, S. Membrane-Permeable Arginine-Rich Peptides and the Translocation Mechanisms. Adv. Drug Deliv. Rev. 2005, 57 (4), 547-558.

(16) Liu, C.; Jiang, K.; Tai, L.; Liu, Y.; Wei, G.; Lu, W.; Pan, W. Facile Noninvasive Retinal Gene Delivery Enabled by Penetratin. ACS Appl. Mater. Interfaces 2016, 8 (30), 1925619267.

(17) Yin, T.; Xie, W.; Sun, J.; Yang, L.; Liu, J. Penetratin Peptide-Functionalized Gold Nanostars: Enhanced BBB Permeability and NIR Photothermal Treatment of Alzheimer's Disease Using Ultralow Irradiance. ACS Appl. Mater. Interfaces 2016, 8 (30), 19291-19302.

(18) Gartziandia, O.; Patricia Egusquiaguirre, S.; Bianco, J.; Luis Pedraz, J.; Igartua, M.; Maria Hernandez, R.; Preat, V.; Beloqui, A. Nanoparticle Transport across in Vitro Olfactory Cell Monolayers. Int. J. Pharm. 2016, 499 (1-2), 81-89.

(19) Raudszus, B.; Mulac, D.; Langer, K. A New Preparation Strategy for Surface Modified PLA Nanoparticles to Enhance Uptake by Endothelial Cells. Int. J. Pharm. 2018, 536 (1), 211-221.

(20) Kamei, N.; Shingaki, T.; Kanayama, Y.; Tanaka, M.; Zochi, R.; Hasegawa, K.; Watanabe, Y.; Takeda-Morishita, M. Visualization and Quantitative Assessment of the Brain Distribution of Insulin through Nose-to-Brain Delivery Based on the CellPenetrating Peptide Noncovalent Strategy. Mol. Pharm. 2016, 13 (3), 1004-1011.

(21) Shahbazi, S.; Bolhassani, A. Comparison of Six Cell Penetrating Peptides with Different Properties for in Vitro and in Vivo Delivery of HPV16 E7 Antigen in Therapeutic Vaccines. Int. Immunopharmacol. 2018, 62, 170-180.

(22) Morris, M. C.; Gros, E.; Aldrian-Herrada, G.; Choob, M.; Archdeacon, J.; Heitz, F.; Divita, G. A Non-Covalent Peptide-Based Carrier for in Vivo Delivery of DNA Mimics. Nucleic Acids Res 2007, 35 (7), e49.

(23) Deshayes, S.; Morris, M.; Heitz, F.; Divita, G. Delivery of Proteins and Nucleic Acids Using a Non-Covalent Peptide-Based Strategy. Adv. Drug Deliv. Rev. 2008, 60 (4), 537547.

(24) Kissinger, C. R.; Liu, B.; Martin-Blanco, E.; Kornberg, T. B.; Pabo, C. O. Crystal Structure of an Engrailed Homeodomain-DNA Complex at $2.8 \AA$ Resolution: A Framework for Understanding Homeodomain-DNA Interactions. Cell 1990, 63 (3), 579590. 
(25) Ledneva, R. K.; Alexeevskii, A. V; Vasil'ev, S. A.; Spirin, S. A.; Karyagina, A. S. Structural Aspects of Interaction of Homeodomains with DNA. Mol. Biol. 2001, 35 (5), 647-659.

(26) Noyes, M. B.; Christensen, R. G.; Wakabayashi, A.; Stormo, G. D.; Brodsky, M. H.; Wolfe, S. A. Analysis of Homeodomain Specificities Allows the Family-Wide Prediction of Preferred Recognition Sites. Cell 2008, 133 (7), 1277-1289.

(27) Daban, J.-R. Electron Microscopy and Atomic Force Microscopy Studies of Chromatin and Metaphase Chromosome Structure. Micron 2011, 42 (8), 733-750.

(28) Silva, E. R.; Listik, E.; Han, S. W.; Alves, W. A.; Soares, B. M.; Reza, M.; Ruokolainen, J.; Hamley, I. W. Sequence Length Dependence in Arginine/Phenylalanine Oligopeptides: Implications for Self-Assembly and Cytotoxicity. Biophys. Chem. 2018, 233.

(29) Decandio, C. C.; Silva, E. R.; Hamley, I. W.; Castelletto, V.; Liberato, M. S.; Oliveira, V. X.; Oliveira, C. L. P.; Alves, W. A. Self-Assembly of a Designed Alternating Arginine/Phenylalanine Oligopeptide. Langmuir 2015, 31 (15).

(30) da Silva, E. R. T.; de Oliveira, E. A.; Fevrier, A.; Nallet, F.; Navailles, L. Supramolecular Polymorphism of DNA in Non-Cationic L-Alpha Lipid Phases. Eur Phys J E Soft Matter 2011, 34 (8), 83.

(31) de Oliveira, E. A.; da Silva, E. R. T.; Fevrier, A.; Grelet, E.; Nallet, F.; Navailles, L.; Oliveira, E. A. de; Silva, E. R. T. da; Février, A.; É, G.; et al. Confinement-Induced Phase Transition in a DNA-Lipid Hydrated Complex. Epl 2010, 91 (2), 28001.

(32) Silva, E. R.; Cooney, G.; Hamley, I. W.; Alves, W. A.; Lee, S.; O’Connor, B. F.; Reza, M.; Ruokolainen, J.; Walls, D. Structural Behaviour and Gene Delivery in Complexes Formed between DNA and Arginine-Containing Peptide Amphiphiles. Soft Matter 2016, $12(45)$.

(33) Strey, H. H.; Podgornik, R.; Rau, D. C.; Parsegian, V. A. DNA-DNA Interactions. Curr. Opin. Struct. Biol. 1998, 8 (3), 309-313.

(34) Sambrook, Joseph; Russell, D. W. Molecular Cloning : A Laboratory Manual, 3rd ed.; Cold Spring Harbor Laboratory Press: Cold Spring Harbor, N.Y, 2001.

(35) Dazzi, A.; Glotin, F.; Carminati, R. Theory of Infrared Nanospectroscopy by Photothermal Induced Resonance. J. Appl. Phys. 2010, 107 (12), 124519.

(36) Dazzi, A.; Prater, C. B. AFM-IR: Technology and Applications in Nanoscale Infrared Spectroscopy and Chemical Imaging. Chem. Rev. 2017, 117 (7), 5146-5173.

(37) Mello, L. R.; Hamley, I. W.; Miranda, A.; Alves, W. A.; Silva, E. R. $\beta$-Sheet Assembly in Amyloidogenic Glutamic Acid Nanostructures: Insights from X-Ray Scattering and Infrared Nanospectroscopy. J. Pept. Sci. 2019, 25 (6), e3170.

(38) Zemb, T.; Lindner, P. Neutrons, X-Rays and Light: Scattering Methods Applied to Soft Condensed Matter, 1st ed.; Elsevier: Amsterdam ; Boston, 2002.

(39) Bartlett, P.; Ottewill, R. H. A Neutron-Scattering Study of the Structure of a Bimodal Colloidal Crystal. J. Chem. Phys. 1992, 96 (4), 3306-3318.

(40) Beaucage, G. Small-Angle Scattering from Polymeric Mass Fractals of Arbitrary MassFractal Dimension. J. Appl. Crystallogr. 1996, 29, 134-146.

(41) Pizzey, C. L.; Pomerantz, W. C.; Sung, B. J.; Yuwono, V. M.; Gellman, S. H.; Hartgerink, J. D.; Yethiraj, A.; Abbott, N. L. Characterization of Nanofibers Formed by Self-Assembly of Beta-Peptide Oligomers Using Small Angle x-Ray Scattering. J Chem 
Phys 2008, 129 (9), 95103.

(42) Schweizer, K. S.; Curro, J. G. PRISM Theory of the Structure, Thermodynamics, and Phase Transitions of Polymer Liquids and Alloys. In Atomistic Modeling of Physical Properties; Monnerie, L., Suter, U. W., Eds.; Springer Berlin Heidelberg: Berlin, Heidelberg, 1994; pp 319-377.

(43) Feig, M.; Pettitt, B. M. Sodium and Chlorine Ions as Part of the DNA Solvation Shell. Biophys. J. 1999, 77 (4), 1769-1781.

(44) Bravo-Anaya, L.; Roux, D.; Soltero Martínez, J.; Carvajal Ramos, F.; Pignon, F.; Mannix, O.; Rinaudo, M.; Bravo-Anaya, L. M.; Roux, D. C. D.; Soltero Martínez, J. F. A.; et al. Role of Electrostatic Interactions on Supramolecular Organization in CalfThymus DNA Solutions under Flow. Polymers (Basel). 2018, 10 (11), 1204.

(45) Kogikoski, S.; Liberato, M. S.; Factori, I. M.; da Silva, E. R.; Oliveira, C. L. P.; Ando, R. A.; Alves, W. A. Polycaprolactone-Polyaniline Blend: Effects of the Addition of Cysteine on the Structural and Molecular Properties. J. Phys. Chem. C 2017, 121 (1), 863-877.

(46) Hammouda, B.; Horkay, F.; Becker, M. L. Clustering and Solvation in Poly(Acrylic Acid) Polyelectrolyte Solutions. Macromolecules 2005, 38 (5), 2019-2021.

(47) Besselink, R.; Stawski, T. M.; Van Driessche, A. E. S.; Benning, L. G. Not Just Fractal Surfaces, but Surface Fractal Aggregates: Derivation of the Expression for the Structure Factor and Its Applications. J. Chem. Phys. 2016, 145 (21), 211908.

(48) Barth, A. The Infrared Absorption of Amino Acid Side Chains. Prog Biophys Mol Biol 2000, 74 (3-5), 141-173.

(49) Mello, M. L. S.; Vidal, B. C. Changes in the Infrared Microspectroscopic Characteristics of DNA Caused by Cationic Elements, Different Base Richness and Single-Stranded Form. PLoS One 2012, 7 (8), e43169-e43169.

(50) Ahmad, R.; Naoui, M.; Neault, J. F.; Diamantoglou, S.; TajmirRiahi, H. A. An FTIR Spectroscopic Study of Calf-Thymus DNA Complexation with Al(III) and Ga(III) Cations. J. Biomol. Struct. Dyn. 1996, 13 (5), 795-802.

(51) Unger, M.; Ozaki, Y.; Pfeifer, F.; Siesler, H. W. 2DCOS and PCMW2D Analyses of MIR/ATR and FT-NIR Spectra Monitoring the Deuterium/Hydrogen Exchange in Liquid D2O. J. Mol. Struct. 2014, 1069 (SI), 258-263.

(52) Zhao, X.; Li, Z.; Liu, W.; Lam, W.; Sun, P.; Kao, R. Y. T.; Luk, K. D. K.; Lu, W. W. Octaarginine-Modified Chitosan as a Nonviral Gene Delivery Vector: Properties and in Vitro Transfection Efficiency. J. Nanoparticle Res. 2011, 13 (2), 693-702.

(53) Kim, M.; Kim, H. R.; Chae, S. Y.; Larson, R. G.; Lee, H.; Park, J. C. Effect of ArginineRich Peptide Length on the Structure and Binding Strength of SiRNA-Peptide Complexes. J. Phys. Chem. B 2013, 117 (23), 6917-6926.

(54) Prata, C. A. H.; Zhang, X.-X.; Luo, D.; McIntosh, T. J.; Barthelemy, P.; Grinstaff, M. W. Lipophilic Peptides for Gene Delivery. Bioconjug. Chem. 2008, 19 (2), 418-420.

(55) Kong, J.; Yu, S. Fourier Transform Infrared Spectroscopic Analysis of Protein Secondary Structures. Acta Biochim. Biophys. Sin. (Shanghai). 2007, 39 (8), 549-559.

(56) Malhotra, P.; Udgaonkar, J. B. How Cooperative Are Protein Folding and Unfolding Transitions? Protein Sci. 2016, 25 (11), 1924-1941.

(57) Lee, C.-C.; Sun, Y.; Huang, H. W. Membrane-Mediated Peptide Conformation Change from Alpha-Monomers to Beta-Aggregates. Biophys. J. 2010, 98 (10), 2236-2245. 
(58) Sun, Y.; Lee, C.-C.; Chen, T.-H.; Huang, H. W. Kinetic Process of Beta-Amyloid Formation via Membrane Binding. Biophys. J. 2010, 99 (2), 544-552.

(59) Barth, A. Infrared Spectroscopy of Proteins. Biochim. Biophys. Acta - Bioenerg. 2007, 1767 (9), 1073-1101.

(60) Tesei, G.; Vazdar, M.; Jensen, M. R.; Cragnell, C.; Mason, P. E.; Heyda, J.; Skepö, M.; Jungwirth, P.; Lund, M. Self-Association of a Highly Charged Arginine-Rich CellPenetrating Peptide. Proc. Natl. Acad. Sci. 2017, 114 (43), 11428 LP - 11433.

(61) Macchi, S.; Nifosì, R.; Signore, G.; Di Pietro, S.; Boccardi, C.; D’Autilia, F.; Beltram, F.; Cardarelli, F. Self-Aggregation Propensity of the Tat Peptide Revealed by UV-Vis, NMR and MD Analyses. Phys. Chem. Chem. Phys. 2017, 19 (35), 23910-23914.

\section{TOC Graphic}

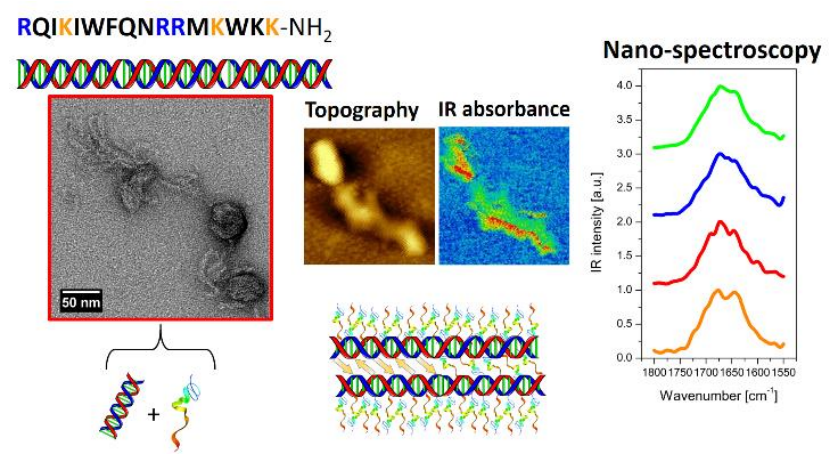

